\title{
AERIAL PLATFORMS (UAV) SURVEYS IN THE VIS AND TIR RANGE. APPLICATIONS ON ARCHAEOLOGY AND AGRICULTURE
}

\author{
E. I. Parisi ${ }^{1}$, M. Suma ${ }^{2}$, A. Güleç Korumaz ${ }^{1}$, E. Rosina ${ }^{2}$, G. Tucci ${ }^{1} *$ \\ ${ }^{1}$ DICEA - Dept. of Civil and Environmental Engineering, University of Florence, Via di Santa Marta 3, Florence, Italy \\ (ericaisabella.parisi@unifi.it, gulec.armagan@gmail.com, grazia.tucci@unifi.it) \\ ${ }^{2}$ DABC - Dept. of Architecture, Built Environment and Construction Engineering, Polytechnic University of Milan, Piazza \\ Leonardo da Vinci 32, 20133 Milan, Italy (arch.marivitasuma@gmail.com, elisabetta.rosina@polimi.it)
}

KEY WORDS: Photogrammetry, Archaeology, Agriculture, UAV, Thermal imaging, multi-sensor, monitoring, documentation

\begin{abstract}
:
The paper presents multi-sensor applications of Unmanned Aerial Vehicles (UAVs) on three different cases of study, belonging to the wide category of Cultural Heritage $(\mathrm{CH})$. The contribution aims to examine the efficacy of different methodological approach of surveys made in VIS and TIR range with aerial platforms. The use of UAV on two archaeological areas, Çatalhöyük site (Konya, Turkey) and the Medicean Villa of Pratolino (Florence, Italy) and an application of precision agriculture in Lamole (Greve in Chianti, Italy) will be presented. In particular, the analysis will focus on the accuracy of the obtained data, in terms of both metric and image quality, the possible information to extract from the IR imaging, the relationship between costs and benefits and the total amount of information that can be gained. The two different fields of research (archaeological and agricultural one) show that there are some similarities in the approaches and which could be the improving to obtain using the aerial survey in the visual and IR bands.
\end{abstract}

\section{INTRODUCTION}

The use of Unmanned Aerial Vehicles (UAVs) as supporting platforms for active sensor in multi-spectral ranges is currently an emerging tool to correlate spatial information derived from RGB data with thermal imaging (Nebiker et al. 2016, Zefri et al. 2018, Deng et al. 2018, Yazici et al. 2018). Promising applications are rapidly becoming common tools for surveillance purposes, military and security controls, hazard area and natural disaster monitoring, fire prevention, structural analysis, tracking traffic and other commercial purposes. Nevertheless, the application in the field of Cultural Heritage $(\mathrm{CH})$, in their widest meaning, is still an actual research topic, not yet extensively explored.

The present study reports the efficacy evaluations of the use of non-destructive imaging, in particular in the Thermal InfraRed (TIR) range, mounted on mobile platforms (UAV) for documentation and monitoring purposes of natural, archaeological and architectural Heritage. In particular, the authors refer of three cases of study that serves to enlarge the discussion of pros and limits that could be overcome in further steps of the research.

The overlapping between the spatial (geometric information from visible - VIS survey) and the spectral (TIR mapping) information can be applied in different fields for documentation and monitoring purposes.

Since the end of 80 's, many researches have been using the information derived from the overlapping of rectified images in the visible and thermal range of the electromagnetic spectrum, to improve the documentation processes and conservation assessment of Cultural Heritage in their sites (Bisoni et al. 2016).

The considerable technological developments made in recent years, allowed to reduce size, weight and price of imaging sensors available for non-destructive analysis of Cultural Heritage. This miniaturization process has led to a progressively integration of multi-spectral sensors on mobile platforms, such as UAV (Bisoni et al. 2016), portable systems and vehicles, in addition to traditional airborne and satellite remote sensing applications. The use of UAV for photogrammetric surveys in the VIS range is a well-established methodology (Chiabrando et al. 2013, Eisenbeiss et al. 2011, Lo Brutto et al. 2014, Masiero et al. 2019, Matese et al. 2015, Rinaudo et al. 2012), while the integration with sensors in different ranges of the electromagnetic spectrum is still an ongoing and innovative research topic.

The advancement of technologies, the decrease of costs and increase of the robustness in devices and software make multisensors applications available for the use in several fields, by integrating and overcoming the traditional techniques of survey. An emerging application field is the documentation and monitoring of an additional branch of $\mathrm{CH}$, the Environmental Heritage and, specifically, the traditional cultivations by drystone walls terracing.

The UNESCO list of $\mathrm{CH}$ types include agriculture since early years of 20th century and dedicates to the World Heritage agricultural landscapes and entire sector of study on the legal framework to list and protect the historic cultivations ${ }^{1}$. One of the first agricultural area that obtained the inclusion in the UNESCO list have been the Tokai region, in 2002, whilst only recently (November 2018) the "Art of dry-stone walling, knowledge and techniques" obtained the recognition as Intangible Cultural Heritage of Humanity ${ }^{2}$. In fact, dry-stone wall terracing is spread all over Europe and world rural areas, as a very typical agricultural landscape. Dry-stone structures are of paramount role in maintaining the environment and landscape, by preventing landslides, floods and avalanches, and against erosion effects and desertification of the land, enhancing biodiversity and creating adequate microclimatic conditions for agriculture (Arnáez et al. 2015, Socci et al. 2019, Wei et al. 2016).

Furthermore, many Italian sites with these particular agricultural landscapes are already part of UNESCO World Heritage Sites

\footnotetext{
* Corresponding author

${ }^{1}$ www.unesco.org

${ }^{2}$ Decision 13.COM 10.b.10
} 
list (Portovenere, Cinque Terre, and the Islands terraced vineyards), and inserted in the FAO Globally Important Agricultural Heritage Systems - GIAHS, (Olive Groves of the Slopes between Assisi and Spoleto).

The Tuscany Region is particularly characterized by dry-stone wall terracing rural landscape. In fact, the historical rural landscape of Lamole, in the Chianti area, is part since February 2018 of the Rural Historic Landscape Catalogue of the Italian Ministry of Agricultural, Food, Forestry Policies. The economic income of the well-known brand of Chianti wine produced in this area is also one of the engines to generate virtuous capital investments for the protection of these historical sites.

The improvement of the tools for assessing the growth of vegetation includes also the image analysis in the IR spectrum. The soil and vegetation temperature distribution has been extensively used as an indicator of their status. As reported by Ludwig and Vijai Singh (Ludwig et al. 2009, Ludwig 2017, Milazzo et al. 1994, Singh et al. 2017) temperature evaluations have been used to check leaf transpiration as a clue of the good health of greenery. Temperature plays also a key role for the specific case of grapevine, in regulating the chemical-physical features (physiology, phenology and photosynthesis) (Ferrini et al. 1995, Kanistras et al. 2013, Martínez-Lüscher et al. 2016) and the final quality of wine. In fact, temperature affects the development of berries, by inducing a differential accumulation of dry matter and sugar concentration (Costa et al. 2010, Gaiotti et al. 2018, Greer et al. 2014, Idso et al. 1981). Precision agriculture is currently a very promising application field, since multispectral sensors, not only in the TIR range, are used to map soil and crops health, water status, microclimate effects and biophysical vegetation indexes (Ahirwar et al. 2019, Baluja et al. 2012, Svensgaard et al. 2014, Turner et al. 2011).

Furthermore, TIR surveys are used within archaeological researches of underlying structures and to estimate the conservation state of the constituent materials. The differences of temperatures resulting on the soil where remains are buried is an excellent clue for their location, keeping constant the best environmental conditions before and during the recapture. As a cons, the presence of uneven soil can prevent the recapture from a short distance, at the ground level, although the short distance recapture is always highly time consuming, especially in the preliminary phase when a general overview is sufficient to locate anomalies to further explore with a more detailed analysis (Hamilton et al. 2016, Mouget et al. 2014).

The integrated data coming from aerial surveys with multisensor responses can also be gathered in modelling and management systems, i.e. BIM and GIS, with additional resources as visualization of the thermal images on the 3D model or insertion of the outputs in geo-localized contexts.

The following paper refers on three cases of study of integrated multi-sensor applications from UAVs: i) the archaeological area of Çatalhöyük Konya, in Turkey, ii) the Medicean Villa of Pratolino in Florence, Italy, iii) the Lamole vineyard in the Chianti region, Italy (protected landscape of Tuscany). The study cases are also examples of possible implementation of the research.

\section{MATERIALS AND METHODS}

For both the study cases the authors performed different aerial surveys using UAVs platforms equipped with sensors in different ranges of the electromagnetic spectrum. Each the aerial campaigns were carried out by planning a first photogrammetric survey in the visible range, followed by TIR surveys. The aim of the VIS inspections has been the production of a Digital Elevation Model (DEM) of the surveyed area and the respective projected orthophoto.

\begin{tabular}{|c|c|c|}
\hline \multicolumn{3}{|c|}{ ÇATALHÖYÜK (KONYA) } \\
\hline \multicolumn{3}{|c|}{ UAV platforms } \\
\hline & VIS & TIR \\
\hline Typology & \multicolumn{2}{|c|}{ Albris Sensefly quadcopter } \\
\hline Weight & \multicolumn{2}{|c|}{$1800 \mathrm{~g}$} \\
\hline Size & \multicolumn{2}{|c|}{$56 \times 80 \times 17 \mathrm{~cm}$} \\
\hline Max speed & \multicolumn{2}{|c|}{ Automatic flight: $8 \mathrm{~m} / \mathrm{s}$-Manual flight: $12 \mathrm{~m} / \mathrm{s}$} \\
\hline Max flight time & \multicolumn{2}{|c|}{ Up to 22 minutes } \\
\hline \multicolumn{3}{|c|}{ Sensors } \\
\hline & VIS & TIR \\
\hline Typology & \multicolumn{2}{|c|}{ Integrated camera - Triple view head } \\
\hline Spectral range & \begin{tabular}{|l|l} 
RGB &
\end{tabular} & Thermal InfraRed \\
\hline Sensor & N.A. & $\begin{array}{l}\text { Thermal overlaid on } \\
\text { main camera stream }\end{array}$ \\
\hline Sensor size & N.A. & N.A. \\
\hline Resolution & $38 \mathrm{MP}(7152 \times 5368 \mathrm{px})$ & $80 \times 60$ pixels \\
\hline Focal length & $8 \mathrm{~mm}$ & N.A. \\
\hline FOV (horizontal) & $63^{\circ}$ & $50^{\circ}$ \\
\hline \multicolumn{3}{|c|}{$\begin{array}{c}\text { MEDICEAN VILLA OF PRATOLINO } \\
\end{array}$} \\
\hline \multicolumn{3}{|c|}{ UAV platforms } \\
\hline & VIS & TIR \\
\hline Typology & \multicolumn{2}{|c|}{ AeroMax 600 multirotor } \\
\hline Weight & \multicolumn{2}{|c|}{$3.9 \mathrm{Kg}$ (incl. supplied camera and battery) } \\
\hline Size & \multicolumn{2}{|c|}{$\begin{array}{l}\text { N.A. } \\
\end{array}$} \\
\hline Max speed & \multicolumn{2}{|c|}{$11 \mathrm{~m} / \mathrm{s}$ (automatic flight) } \\
\hline Max flight time & \multicolumn{2}{|c|}{ Up to 12 minutes } \\
\hline \multicolumn{3}{|c|}{ Sensors } \\
\hline & VIS & TIR \\
\hline Typology & SONY Alpha NEX-5 & OPTRIS PI 450 \\
\hline Spectral range & RGB & $\operatorname{TIR}(7.5-13 \mu \mathrm{m})$ \\
\hline Sensor & $\begin{array}{c}\text { Exmor APS-C HD } \\
\text { CMOS } \\
\end{array}$ & FPA, uncooled \\
\hline Sensor size & $23.7 \times 15.6 \mathrm{~mm}$ & $25 \times 25 \mu \mathrm{m}$ \\
\hline Resolution & $14.2 \mathrm{MP}(4592 \times 3056)$ & $382 \times 288 \mathrm{px}$ \\
\hline Focal length & $22 \mathrm{~mm}$ & $8 \mathrm{~mm}$ \\
\hline FOV (horizontal) & N.A. & $62^{\circ} \times 49^{\circ}$ \\
\hline Output & JPEG image & .RAVI video \\
\hline Weight & N.A. & $320 \mathrm{~g}$ \\
\hline \multicolumn{3}{|c|}{ LAMOLE VINEYARD } \\
\hline \multicolumn{3}{|c|}{ UAV platforms } \\
\hline & VIS & TIR \\
\hline Typology & DJI Phantom 4 Pro & customized hexacopter \\
\hline Weight & $1388 \mathrm{~g}$ & N.A. \\
\hline Diagonal size & $350 \mathrm{~mm}$ & N.A. \\
\hline Max speed & $72 \mathrm{kph}$ (S-mode) & N.A. \\
\hline Max flight time & Approx. $30 \mathrm{~min}$ & N.A. \\
\hline \multicolumn{3}{|c|}{ Sensors } \\
\hline & VIS & TIR \\
\hline Typology & DJI FC6310 & OPTRIS PI450 \\
\hline Spectral range & RGB & TIR $(7.5-13 \mu \mathrm{m})$ \\
\hline Sensor & 1'”CMOS & FPA, uncooled \\
\hline Sensor size & $13.1 \times 8.7 \mathrm{~mm}$ & $25 \times 25 \mu \mathrm{m}$ \\
\hline Resolution & 20 MP (5472 x 3648 px) & $382 \times 288 \mathrm{px}$ \\
\hline Focal length & $8 \mathrm{~mm}$ & $8 \mathrm{~mm}$ \\
\hline FOV & $84^{\circ}$ & $62^{\circ} \times 49^{\circ}$ \\
\hline Output & JPEG image & .RAVI video \\
\hline Weight & $300 \mathrm{~g}$ & $320 \mathrm{~g}$ \\
\hline Temp. resolution & N.A. & $\pm 2{ }^{\circ} \mathrm{C}$ \\
\hline
\end{tabular}


Table 1. UAVs and sensors used in the different cases of study

The second step was the extraction from the TIR images/videos of the suitable information, in the form of orthomosaics to overlap with the spatial information. Each case of study has required a specific planning to adapt to the final aims of the surveys, by using different UAVs and sensors (see Table 1).

\section{1 Çatalhöyük in Konya, Turkey}

Çatalhöyük is one of the most ancient and prominent archeological sites in Turkey, listed in the UNESCO World Heritage, recently granted by the Getty Conservation Institute. It was built in the Neolithic period, and located near the town of Çumra within the province of Konya. The site consists of two hills on the Southern Anatolian Plateau, with archaeological testimonies of Neolithic occupation between $7400 \mathrm{BC}$ and 6200 $\mathrm{BC}$ and the Chalcolithic period, from $6200 \mathrm{BC}$ to $5200 \mathrm{BC}$. Çatalhöyük provides important evidence of the transition from settled villages to urban agglomeration, which was maintained in the same location for over 2,000 years.

The aim of the survey has been to combine integrated survey technologies (terrestrial laser scanning data and aerial data from UAV) to improve and get a complete documentation of archaeological area and to investigate the potentials of UAVs coupled with thermal camera for detection of buried architectural ruins (Guleç Korumaz 2017).

2.1.1 Data Acquisition: two aerial surveys were performed on the Eastern Mound North Peak Archaeological Area, of both the entire area and inside the shelter of the excavations. We will present only the methodology adopted for the shelter survey, since it was performed both in the VIS and TIR range. The aim was to combine VIS and TIR data to check the anomalies for guiding future excavations. For aerial data an Albris Sensefly quadcopter was used as UAV platform equipped with an integrated multi-sensor TripleView camera, which allows to switch between HD and thermal video imagery, live during the flight, plus a wide-angle video-camera (refer to Table 1 for UAV and sensor specifications). Thermal camera has an overlay of $80 \times 60$ pixels on the main camera stream ${ }^{3}$. One VIS and five TIR flights were conducted over the archaeological area inside the shelter (7:50, 10:38, 13:29, 17:25 and 18:51). The GCPs were measured with RTK GPS (Real Time Kinematic Global Positioning System) and have an accuracy of $2-3 \mathrm{~cm}$. Unfortunately, they moved during the data acquisition process, since it was not possible to fix them on an archaeological area, and the GPS signal was very weak inside the shelter, thus they were not used for the georeferencing process. Due to the difficulties of flying in a closed area and to the weak GPS signal, a manual flight with remote control was carried out by using eMotion 3 software. The flight height was fixed at $4.81 \mathrm{~m}$ because of the shelter different height, from $5.5 \mathrm{~m}$ up to $10 \mathrm{~m}$. Total field work was completed in one day.

2.1.2 Data processing and visualization: in this study PhotoScan 1.1.5 was used for aerial image processing in the VIS range. Image alignment was carried out with 373 cameras without GCPs, as above mentioned. The coordinate system of the project was selected as WGS 84 (EPSG::4326).

For TIR processing, measures of inside and outside temperature, soil and ambient relative humidity were registered. The resulting thermal images were already overlapped with the RGB ones in the number of 130 (7:30 flight), 155 (10:38), 171 (13:29), 139 (17:25) and 149 (19:00).

\footnotetext{
${ }^{3}$ www.sensefly.com
}

The alignment of thermal images with SfM procedures and the creation of an orthophoto was not possible since the raw information of thermal images were associated to the VIS background.

\subsection{Medicean Villa of Pratolino in Florence}

Villa Demidoff is the current name of the ancient Medicean Paggeria of Pratolino, Parco Mediceo di Pratolino which is located on the Florentine hills along the Via Bolognese heading into the Mugello valley. The Villa was requested by the Grand Duke of Tuscany, Francesco I de' Medici and designed by Bernardo Buontalenti in 1568. The park has great interest with its artificial grottoes, water tricks and statues, in particular, the Colossus of the Apennines (1579-1580) by Giambologna.

The aim of the survey has been to test the methodology of thermal images collection using UAV in order to reveal subsurface cultural features of the archaeological area. Furthermore, the final goal has been the production of data in terms of feature visibility in non-destructive way with minimum costs.

2.2.1 Data Acquisition: in this project, an AeroMax 600 drone kindly provided by MicroGeo s.r.l. was used, equipped with a SONY Alpha Nex-5 camera for VIS data collection and with an OPTRIS PI 450 for thermal analysis (see Table 1 for further details). Two flights were conducted to survey the entire area in the VIS range. The flight height was set to $50.5 \mathrm{~m}$ and the images were acquired at 11:21 and 12:01 with 10 minutes flight duration. The sidelap was $60 \%$ and overlap $40 \%$, with a GSD of $1 \mathrm{~cm}$. At the end of two flights, a total of 108 images were acquired. The flight trajectory and the image acquisition points were calculated depending on the scale, camera parameters, flight height, dimension of the area and the overlaps in DJI Ground Control Station software. For the images georeferencing, a total of 12 GCPs (black and white A4 size targets) were distributed all over the surveyed area. Using a total station, their positions were recorded within the local reference system. Furthermore, 15 GCPs targets were covered with aluminium foil in order to be visible also from the TIR sensor, thanks to the low emissivity of aluminium $(0.09 \varepsilon)$.

Five more flights were conducted over the same area with the thermal camera, to register thermal videos in different period of the day to see diurnal temperature change on area $(7: 38,8: 43$, 9:16, 15:16, 19:00).

The necessity of multiple flights was due to the low FOV and the limited battery duration. Flight height was chosen as $25 \mathrm{~m}$ with $2.4 \mathrm{~cm}$ GSD and image footprint of $23.99 \times 18.02 \mathrm{~m}$. The $30 \mathrm{~Hz}$ speed allowed frame extraction from the video with $80 \%$ or greater overlap. According to Lundén (Lundén 1985), a suitable time for registration is spring time when the surface of the ground is drying out so this field survey was conducted at $8^{\text {th }}$ April 2015.

2.2.2 Data processing and visualization: in this case study, the methodology has consisted of two parallel workflows, one related to VIS images processing to get an orthophoto and the other one to obtain a thermal orthomosaic. The process followed to obtain the VIS orthophoto is a common SfM procedure for UAV photogrammetry. Image alignment was carried out with 99 cameras of 108 with 27 GCPs.

The steps followed for the thermal orthomosaic are similar but the starting output was a .RAVI video instead of images. The obtained raw data (first flight of 7.38) were processed in the specific software Optris PI Connect (v. 2.9.2147). After setting up the project parameters, snapshots were acquired at specific intervals ( 5 seconds) to obtain $80 \%$ of sidelap and saved as 
.TIFF format. The obtained files were then processed in Agisoft PhotoScan as common images. After image alignment, the aluminium GCPs targets were used to georeference the thermal cloud point with the VIS one. Finally, a DEM and a thermal orthomosaic was created. Further overlapping with previous analysis and historical map was also made. Also, thermal profiles were obtained to study the behaviours of selected anomalies.

\subsection{Lamole vineyard in Tuscany, Italy}

The terraced vineyard of Lamole is placed within the municipality of Greve in Chianti (Florence, Italy) and represents a relevant example of agricultural terracing sites. The study has been carried out in the Grospoli terraced vineyard, in the Chianti Classico region, which produces Sangiovese, Petit Verdot, Cabernet Sauvignon cultivars.

The aim of the survey has been to detect the thermal dynamics of a vineyard grown on a dry-stone wall terraced land, using a TIR sensor mounted on a UAV, coupled with a common RGB survey. In particular, the final goal has been to test strengths and weaknesses of the integration of these two sensors on common platforms, as well as the possible thermal effect of dry-stone walls on vineyard microclimate, since stones can influence the temperature patterns of the field, thus grape ripening and quality.

2.3.1 Data Acquisition: A single flight was performed with a DJI Phantom 4 Pro equipped with DJI FC6310 integrated digital RGB camera (see Table 1 for further details), on the vineyard for the VIS photogrammetric survey. The flight plan was realized with UgCS software, with a GSD of $2 \mathrm{~cm}$. The flight plan consisted of 9 swipes, with forward overlapping of $80 \%$ and sidelap of $70 \%$. The images were acquired with nadiral camera at a constant speed of $5 \mathrm{~m} / \mathrm{s}$ and altitude of $70 \mathrm{~m}$ Above Ground Level (AGL).

As reported in section 2.2.1, the georeferencing of the photogrammetric survey was made by using 10 GCPs, materialized as targets functional for both visible and thermal survey: $60 \times 60 \mathrm{~cm}^{2}$ panels covered with aluminium foil and marked with black sprayed triangles, distributed around the surveyed vineyard. The positioning measures for each target were carried out with the Global Navigation Satellite System (GNSS) TOPCON GR3. The coordinate system used in all data processing is ETRS89/UTM32N (EPSG:25832). The GCPs accuracy is about $1 \mathrm{~cm}$.

The flight campaign for the thermal data capture was carried out with the same equipment used for the Medicean Villa of Pratolino. Two distinct flights in the same day, at 8.50 and 15:00, were performed. The flight plan was realized with Mission Planner software, by setting the suitable parameters in order to have a GSD of $11 \mathrm{~cm}$. The flights pattern consisted of 12 swipes, with forward overlapping of $80 \%$ and sidelap of $63 \%$. The radiometric video sequences were acquired with nadiral orientation at a constant speed of $3 \mathrm{~m} / \mathrm{s}$ and altitude of $40 \mathrm{~m}$. The same targets used for RGB photogrammetry were used for georeferencing the two thermal orthomosaics. Some other panels painted in black and white, onto the aluminium foil were used as delimited areas for pre-flight calibration, as well as some temperature measures of the ground as references.

2.3.2 Data processing and visualization: The 206 images acquired for the VIS flight were processed with Agisoft Photoscan (version 1.2.6 build 2834). After image alignment, GCPs were collimated and associated to their GNSS coordinates, for georeferencing and scale the photogrammetric model. A set of 7 of the 10 total collimated targets were used as
GCPs, while 3 of them were used as Check Points (CP). MultiView Stereo (MVS) algorithms were then used to obtain the dense cloud, from where the DEM of the surveyed area was generated to obtain the final an orthophoto projection.

For what concerns TIR measures, the final values of ambient temperature and emissivity were kept as default, $\mathrm{T}_{\text {amb }} 23^{\circ} \mathrm{C}$ and $\varepsilon=1$ (vegetation usually has high values of emissivity, around 0.98 ) during the data processing step. For this reason, all the resulting thermal values must be considered only as qualitative information, because for absolute values a previous radiometric calibration would have been made. Since the outputs of the thermal survey were radiometric videos, a procedure for frame extraction has been adopted, in order to obtain pictures combined with the thermal information to use in the photogrammetric project, as extensively reported in Tucci et al. 2019.

\section{CASES OF STUDY RESULTS}

\subsection{Results of Çatalhöyük site survey}

The images obtained from the VIS flight were aligned without using the GPS measured GCPs, as mentioned in section 2.2.1. The dense point cloud model was created in high quality parameter $(345,091,208$ points) to produce a Digital Elevation Model (DEM) with a resolution of $1.63 \mathrm{~mm} /$ pix and a density of 37.9 points $/ \mathrm{cm}^{2}$. The final total covered area was $633 \mathrm{~m}^{2}$ with a ground resolution of $0.81 \mathrm{~mm} / \mathrm{px}$ with reprojection error of 1.12 px and RMSE of 0.184 px.

The results of thermal imaging have been reported in Figure 1, where the overlapping between the TIR and the RGB frames is clearly visible.

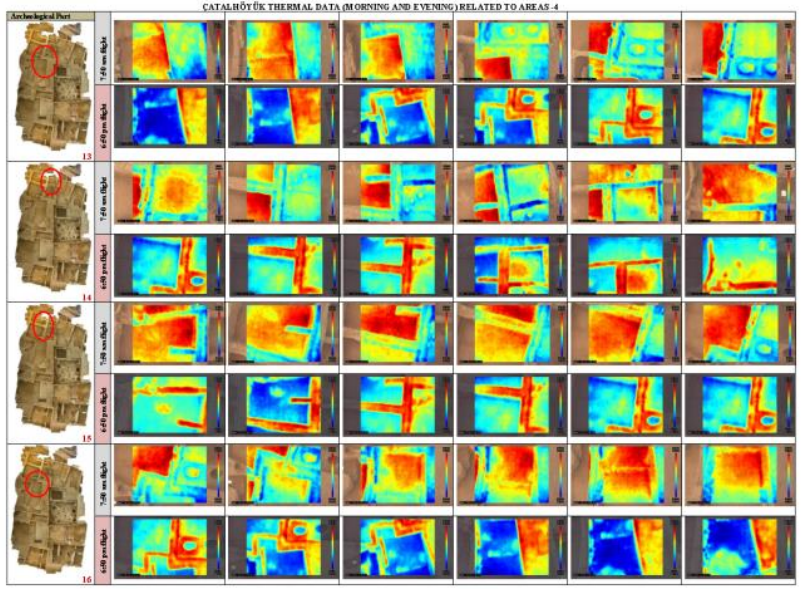

Figure 1: VIS images and TIR thermograms from the archaeological site of Konya (Turkey). The frames highlight the overlapping between the VIS information and the thermograms, thus preventing any photogrammetric processing of the images

\subsection{Results of Medicean Villa of Pratolino survey}

After image alignment of 99 cameras and georeferencing with 27 GCPs, the dense point cloud model was created in high quality parameter $(45,398,256$ points). The resolution of following DEM was $2.13 \mathrm{~cm} / \mathrm{px}$ and point density of the model was 2.190003 points $/ \mathrm{m}^{2}$. A total area of $0.0382 \mathrm{~km}^{2}$ was covered with $1.07 \mathrm{~cm} / \mathrm{px}$ ground resolution and $1.78 \mathrm{px}$ reprojection error; RMSE values were $2.73 \mathrm{~cm}$ and $0.632 \mathrm{px}$.

The thermal orthomosaic obtained from photogrammetric reconstruction of the extracted frames has been reported in Figure 2. 

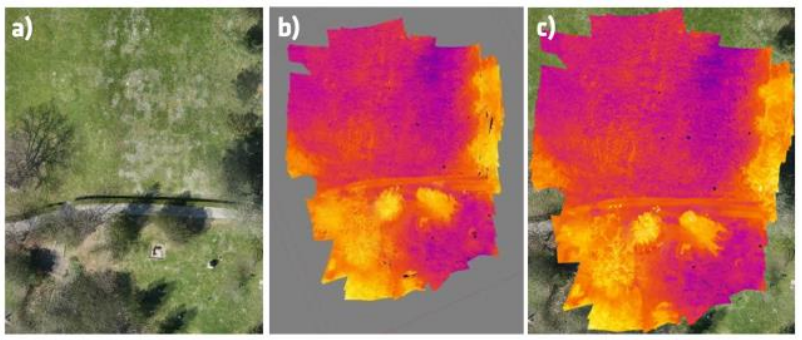

Figure 2: Orthoimages in the VIS and TIR range of the

Pratolino Park in Tuscany (Italy). In particular, a) refers to a part of the VIS orthoimage, b) represents the thermal orthomosaic and c) the overlapping between the two

\subsection{Implementation of the procedure for drone survey of archaeological areas and use of the results}

In the application on archaeological areas, IR aerial imaging and mapping results very useful to locate buried remains not in sight. Nevertheless, to improve the effectiveness of the air survey, it is necessary a direct overview of archaeologists and technicians expert in IR recapture/mapping, to assess the features of the soil, as grain size and sorting, pebbles, the presence of vegetation, water springs or creeks, ponds (although seasonal or temporary), etc.

The use of IR-reflective targets is strongly recommended for locating the detected buried ruins and georeferencing the final maps, especially in the open spaces and without reference points. IR-reflective targets should be large enough to be identified at the flight distance by at least $4 / 16$ pixel on the screen (representing the signal of the matrix of FPA sensors). In fact, if one part of the matrix of sensor or one and more pixel of the screen is not working, the missing part is filled by the average value of the surrounding pixel. If the target is too small, and it coincides with the missing sensor/pixel, the recovery information prevents any possible detection of the target. Moreover, it is mandatory to repeat the flight at different condition of the solar irradiation, in the same day, for comparing the temperatures of the soil at different hours in the same day. Cloudy sky could be helpful to obtain a map of the soil without shadowing due to the presence of trees and elevation. Because of the thermal inertia of the soil, although the surface is not under solar irradiation at the time of the recapture, the effects of shadowing occurred up to 1-3 hours before the scanning could cause the uneven distribution of the ground temperature, resulting in false alarm for the detection of the researched thermal anomalies.

Finally, thermal scanning and images reviewing is not enough to detect the remains; on the contrary, the interdisciplinary collaboration of historians, archaeologists, expert of image treatment and maps is fundamental for detect the traces and where to insist and deepen the research.

\subsection{Results of Lamole vineyard survey}

The processing of the 206 pictures from the VIS flight resulted to a $2 \mathrm{~mm}$ GSD orthophoto with a pixel size of $2.41 \times 2.41 \mu \mathrm{m}^{2}$. After images alignment and georeferencing with GCPs coordinates, a dense cloud of 110,536,245 points was generated. Successively, a DEM surface model was created with a resolution of $4 \mathrm{~cm} /$ pix and point density of 772 points $/ \mathrm{m}^{2}$. The statistical values of the external orientation are listed as RMSE and reported in Table 2.

The different spectral range and the lower spatial resolution of the TIR sensor compared to the VIS one resulted in orthomosaics with ground resolution of $12 \mathrm{~cm} /$ pix both. In fact, the lack of information in the grey-scaled thermograms for the feature-matching procedure of the software, gave lower number of tie points as a result, compared to the VIS orthophoto.

The same GCPs used to scale and georeferencing the VIS 3D model, gave also different values of RMSE for the TIR projects (see Table 2). The higher error values associated to the TIR CPs could be attributed to the difficulties in exactly picking the centre of the targets, mainly because of the low image quality, thus resulting in wrong identifications.

The two generated dense clouds had similar sizes, of 964,066 points for the morning and 880,995 points for the afternoon. The DEM surface model was finally created with a resolution of $23 \mathrm{~cm} /$ pix and 18 points $/ \mathrm{m}^{2}$ for both.

Figure 3 reports one of the two orthomosaics (morning) scaled differently, in function of their maximum and minimum temperature, to enhance visualization. In particular the temperature range is of $14.8-18.3{ }^{\circ} \mathrm{C}$ (Tucci et al. 2019).

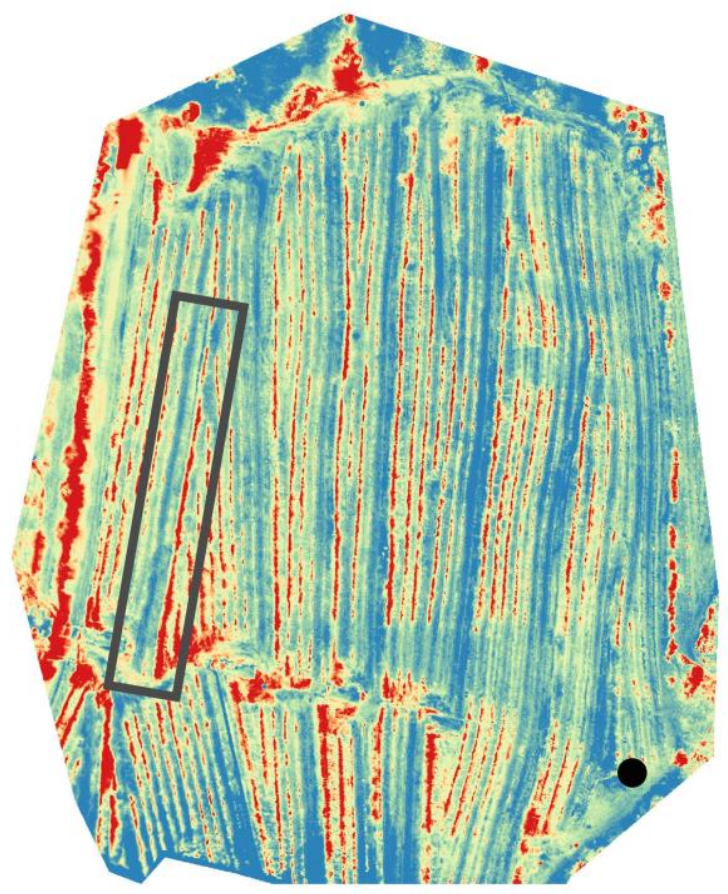

Figure 3: TIR orthoimages of the Lamole vineyard in the Chianti region (Italy), recapture at morning. Soil temperature was $17.4^{\circ} \mathrm{C}$ (black dot), air temperature $15.6^{\circ} \mathrm{C}$ and R.H. $95.8 \%$. The rectangular frame represents an area with about $3.5-4^{\circ} \mathrm{C}$ of difference between internal row (in blue, colder and facing the dry-stone wall) and the external row (in red, warmer and placed on the top of the dry-stone wall)

\begin{tabular}{lllll}
\hline & \multicolumn{2}{c}{ Control Points } & \multicolumn{2}{c}{ Check Points } \\
\hline & RMSE & RMSE & RMSE & RMSE \\
& {$[\mathbf{c m}]$} & {$[\mathbf{p i x}]$} & {$[\mathbf{c m}]$} & {$[\mathbf{p i x}]$} \\
RGB & 1.59 & 0.13 & 2.52 & 0.15 \\
TIR morning & 0.34 & 0.05 & 5.43 & 0.05 \\
TIR afternoon & 0.45 & 0.06 & 11.4 & 0.06 \\
\hline
\end{tabular}

Table 2. Statistic values of the external orientation listed as RMSE.

3.4.1 Use of the results for the agricultural field: the outputs of the described process is a map, implemented in a GIS software, useful for supporting the decision making process of agriculture management. In fact, environmental temperature may affect the time of grapes collection: if it delays, the grape loses its water and the concentration of sugar increase, thus determining a higher alcohol concentration at the end of the 
wine produced. Therefore, the TIR aerial survey of plants may be a useful tool to help the collection time, depending on the condition of sun irradiation that the grape receives and the influence of dry-stone walls. Moreover, in the terrace lands, the presence of the soil retaining walls can affect the temperature of air around the grapes closer to the walls, due to the thermal inertia of the stone composing the walls. The risk could be to obtain final products with different qualities. The aerial TIR survey support the decision of the best time for harvesting that in this case could be different for the grape lines closer to the walls.

Another useful application of TIR map is the location of sick sprigs. One of the symptoms is the decrease of the evaporation the leave faces. The evaporation of the water content in the leaves results as a lower temperature of the surfaces where evaporation occurs up to some decimal of grades, therefore it is detectable with the TIR. In case of too high temperature of the leaves (in comparison with the seasonal average), the data analysis will be and alert for a fast intervention (further inspections, watering, chemical analysis) (Ludwig et al. 2009, Ludwig 2017, Milazzo et al. 1994).

Furthermore, TIR detects the temperature of the soil, thus helping to check the homogeneity of the water irrigation of the soil (because of the lowering temperature of soil due to the water evaporation after irrigation). Therefore, the aerial inspection (visual and IR) has the advantage to help focusing on the emergency, lowering the costs of surveillance and prompt intervention. At present, the application of aerial surveillance devoted to vineyard as well as other vegetation (olivea and citrus trees) is increasingly being used as monitoring tool.

The main obstacle is that fruit trees have large foliage, therefore, the survey from the drone could not be complete in the areas where the leaves hide the soil. The evaluation of the plant health is more complex, because it requires to integrate the information coming from the survey at two highs, over and below the leaves. Up to now, the easier and more convenient use of drone is the investigation on low-height crops, because it is possible to detect both the condition of the vegetation and the soil by the same flight.

3.4.2 Other applications, Olive trees and Xylella: The regional law of Puglia Region ${ }^{4}$ promoted the protection and valorization of the olive trees. Olive cultivation is dating back to some thousands of years and it reveals the exceptional features in Puglia. Since few years ago, a bacterium spread causing the death of many trees in Puglia and the authorities required to cut them before spreading the bacteria. Because of the wide area under risk of this disease, it is impossible to directly inspect all the trees. Therefore, a preventive monitoring started for detecting the spread of xylella bacteria and saving the monumental olive trees (Calderon Madrid et al. 2015, ZarcoTejada et al. 2018). In 2018 a study referred on the possibility to monitor wide areas and locate the trees that have a lower vegetation activity, thus potentially sick. The evaluation is approximate, because a low increase of vegetation could be caused by sickness as well as poor watering, nevertheless it is useful to limit the areas to directly inspect.

\subsection{Implementation of the procedure for the drone survey of cultivation and use of the results}

The reported analysis pinpointed that environmental conditions plays a fundamental role in valuable TIR recapturing. The use of temperature probes in the soil, during the recapture, is

\footnotetext{
${ }^{4}$ L.R. 4 giugno 2007, $\mathrm{n}^{\circ} 14$ "Tutela e valorizzazione del paesaggio degli ulivi monumentali della Puglia"
}

necessary to compare the TIR data on the surface temperature and the direct measurements, in addition to calibrate the post processing of the thermal images themselves. The presence of large trees (especially with large foliage), could be an obstacle for inspecting the soil, both for the obstacle itself and the shadowing effect, that prevent solar irradiation. Therefore, the time (day, hour and season) of the recapture has a main role to be effective. The choice of the time depends on the kind of cultivation and the aim of the investigation. The recapture during the main vegetative season (spring) is the best to inspect trees with large foliage, conifers could be under inspection in many different seasons. The evaluation of the fruit harvest time requires to inspect the trees during the summer. On the contrary, the evaluation of the fungi and bacteria attack can be done in different time of the year. The experts of recaptures, together with the expert of agronomy, will evaluate the best time for the inspection. The thermal recapture described in section 2.3.1 has been done twice in a day, but more flights along the day should be preferred to evaluate sun irradiation and heat accumulation in the soil and walls during the daytime. Different aim can require different time of recapture. For example, monitoring particular time of the year in which the decision for harvesting or spreading antiparasitic is crucial. The seasonal monitoring helps to verify the amount of solar radiation reaching the cultivation. As seen in the previous paragraph, the thermal inertia of the walls contributes to accumulate heat in the day and slowly diffuse it after the sunset. In addition, the walls protect the closer grapes from wind. Therefore, the microclimate of the grapes closer the walls has less variation of the air temperature than the one of the grapes far from the walls. To have a seasonal, extensive check of the temperature gap in the soil in the whole cultivated land can improve the production preventing waste of the collected goods.

\section{RESULTS AND CONCLUSIONS}

At present, the diffusion of the survey by remote sensing is increasingly reducing the costs thanks to the continuous improvement of the technological components of the devices and software for the data processing (improvement of the graphic result and the spatial distribution).

Therefore, the new applications are easier to use and can be utilized for different purposes that were not typical at the beginning, for example agriculture monitoring and the detection of buried archaeological remains.

The resulting 3D maps coming from the survey data help to manage the cultivation both in terms of irrigation and nitrogen distribution in the soil surface (Costa et al. 2010, Ahirwar et al. 2019). The output of the better management is the reduction of costs, the improvement of ecologic management of the process and profitability of the agriculture company. The distribution of water and nourishing can be done where and when is necessary, according to the culture requirements and the chemical features of the soil. By visual/thermal air survey, it is possible to achieve the map of the Normalised Difference vegetation index (NDVI) precisely and fast for keeping under control the health of vegetation. The evaluation of extended land allows the agronomists to reduce the time for controlling the fields, therefore they can rapidly overview the place where the need is higher and intervene with the best solutions. For example, up to the present the initial phase of the bacteria attack was considered asymptomatic, because it was not possible to detect the reaction of the vegetation under attack. On the contrary, IR imaging showed that the healthy condition of the vegetation changes since the very beginning of the attack.

In the case of Xylella infestation in Puglia, the agriculture experts associated the initial disease of the grapes with a 
reduction of the leave transpiration, resulting in a higher surface temperature of the foliage, although the color and other features of the grapes did not change at all.

Therefore, the use of IR improves effectively the prevention of spreading disease and the prompt delivery of the treatment. Finally, the watering not exceeding the required amount has ecological consequences, as well as the delivery of nourishing and antiparasitic products only and where is strictly necessary. Some drones have been useful also for disseminate small larvas of species that biologically contrast the parasite.

\subsection{Pro and cons: UAV and TIR}

The use of thermal camera on drones has many advantages. In particular the possibility of flying on wide areas (within the limitations due to the batteries duration) in a short time and low costs is a warranty of acquiring many data. Nevertheless, the processing phase is slower because capturing the thermograms from the video and their range optimization is time consuming. Therefore, the use is appropriate for moderately large extension of lands. At present, the equipment (TIR cameras) allows to reach the accuracy of some $\mathrm{cm}$ and this is a great improvement of the technology even if it is not yet comparable with the results of the more robust methods for the VIS range. The support of technicians remains mandatory to extract the information from the data.

The thermal analysis of the land is useful to localize the areas suffering of vegetation stress and to detect the cause of the stress. The comparison among the visual and IR images is based on the light reflection and difference of the temperature of the foliage and aims to detect the health of the leaves, revealing the presence of bacteria and fungi and lack/abundance of water and nourishing. The application on archaeological sites is mainly for detecting unexpected thermal anomalies of the soil revealing possible buried remains. Despite numerous environmentally factors that could prevent an even distribution of the surface temperature, the recapture at IR is promising, especially in the dry, homogeneous soils and buried objects is located with different thermal properties from the soil: in this cases, the temperature of surface where the object is could sharply change during the heating exchange with the air, during or after the solar irradiation. The depth of the object could be a further limitation, indeed: generally speaking, the best results could be achieved where the objects are less than $50-80 \mathrm{~cm}$ underneath the surface.

The study underlined that any possible improvement of technology hardware and software could highly increase the reliability and feasibility of these applications.

\subsection{The evolution of the methodology}

The use of TIR imaging for photogrammetric reconstruction of 3D models is still an ongoing research topic. Furthermore, the characteristics of the different thermal sensors mounted on UAVs and the final outputs of raw data, determine differences in the data processing. The evolution of the approach is clearly highlighted by the different methods adopted for the three cases of study: i) for the Çatalhöyük archaeological site, the photogrammetric process could not be applied, since the resulting output from the integrated VIS/TIR sensors were overlapped images, not usable for this approach; ii) in the second case of study, the Medicean Villa, a further step was made, since the thermal camera recorded radiometric videos, from where single frames were extracted and treated as common images to use in the photogrammetric workflow but keeping only a color scale as thermal information; iii) the last case of study, Lamole vineyard, represents the most evolved method, up to know, of extracting both thermograms from the videos but keeping also the thermal information in raster files, integrated in a GIS software for statistical temperature analysis.

\section{ACKNOWLEDGEMENTS}

The authors wish to thank the MicroGeo s.r.l. company for having kindly provided the tested UAV platform coupled with the TIR sensor and their flight operator for the Mediacean Villa of Pratolino and the Lamole vineyard surveys.

This work is based upon work supported by the "GAMHer project: Geomatics Data Acquisition and Management for Landscape and Built Heritage in a European Perspective", (PRIN2015 n.2015HJLS7E).

\section{REFERENCES}

Ahirwar, S., Swarnkar, R., Bhukya, S., Namwade, G., 2019. Application of Drone in Agriculture, International Journal Curr. Microbiological Applied Science, 8, 2500-2505. doi.org/10.20546/ijcmas.2019.801.264

Arnáez, J., Lana-Renault, N., Lasanta, T., Ruiz-Flaño, P., Castroviejo, J., 2015. Effects of farming terraces on hydrological and geomorphological processes. A review. CATENA, 128, 122-134. doi.org/10.1016/j.catena.2015.01.021.

Baluja, J., Diago, M. P., Balda, P., Tardaguila, J., 2012. Assessment of vineyard water status variability by thermal and multispectral imagery using an unmanned aerial vehicle (UAV). Irrig. Sci., 30. doi.org/511-522. 10.1007/s00271-012-0382-9

Bison, P., Dezzi Bardeschi, M., Grinzato, E., Kauppinen, T., Tucci, G., 1996. Infrared thermal scanning as a methodology for survey of facades Palazzo della Ragione, Milan, Italy, Thermosense XVIII, Orlando USA. doi.org/10.1117/12.235367.

Calderon Madrid, R., Navas Cortés, J.A., Zarco-Tejada, P.J., 2015. Early Detection and Quantification of Verticillium Wilt in Olive Using Hyperspectral and Thermal Imagery over Large Areas. Remote Sensing, 7, 5584-5610. doi.org/10.3390/rs70505584

Chiabrando, F., Lingua, A., Piras, M., 2013. Direct photogrammetry using UAV: Tests and first results. ISPRS Int. Arch. Photogramm. Remote Sens. Spat. Inf. Sci., XL-1/W2, 8186. doi.org/10.5194/isprsarchives-XL-1-W2-81-2013.

Costa, J.M., Grant, O.M., Chaves, M.M., 2010. Use of Thermal Imaging in Viticulture: Current Application and Future Prospects. Methodologies and Results in Grapevine Research, Delrot, S., Medrano, H., Or, E., Bavaresco, L., Grando, S., Eds.; Springer: Dordrecht, The Netherlands, 2010, 135-150. doi.org/10.1007/978-90-481-9283-0_10

Deng, L., Mao, Z., Li, X., Hu, Z., Duan, F., Yan, Y., 2018. UAV-based multispectral remote sensing for precision agriculture: A comparison between different cameras. ISPRS Journal of Photogrammetry and Remote Sensing, 146, 124-136. doi.org/10.1016/j.isprsjprs.2018.09.008.

Eisenbeiss, H., Sauerbier, M., 2011. Investigation of UAV systems and flight modes for photogrammetric applications: Investigation of UAV systems and flight modes. Photogramm. Rec., 26, 400-421. doi.org/10.1111/j.1477-9730.2011.00657.x.

Ferrini, F., Mattii, G.B., Nicese, F.P., 1995. Effect of Temperature on Key Physiological Responses of Grapevine Leaf. Am. J. Enol. Viticult., 46, 5, 375-379.

Gaiotti, F., Pastore, C., Filippetti, I., Lovat, L., Belfiore, N., Tomasi, D., 2018. Low night temperature at veraison enhances 
the accumulation of anthocyanins in Corvina grapes (Vitis vinifera L.). Sci. Rep., 8. doi.org/10.1038/s41598-018-26921-4.

Greer, D., Weedon, M., 2014. Temperature-dependent responses of the berry developmental processes of three grapevine (Vitis vinifera) cultivars. N. Z. J. Crop Hortic. Sci., 42, 233-246. doi.org/10.1080/01140671.2014.894921.

Guleç Korumaz S.A., Improved documentation of Cultural Heritage using Digital Photogrammetry with Visible and Thermal Images from Unmanned Aerial Vehicles (UAV), Tesi di Dottorato in Process, materials and constructions in civil and environmental engineering and for the protection of the historicmonumental heritage, Technische Universitat Braunschweig and Università degli Studi di Firenze, a.a. 2016/2017, tutors: Prof. G. Tucci and W. Niemeier.

Hamilton, S., Stephenson, J., 2016. Testing UAV (drone) aerial photography and photogrammetry for archaeology, 1-43. doi.org/10.13140/RG.2.1.4306.3443

Idso, S.B., Jackson, R.D., Pinter, P.J., Reginato, R.J., Hatfield, L.J., 1981. Normalizing the stress-degree-day parameter for environmental variability. Agric. Meteorol., 24, 45-55.

Kanistras, K., Martins, G., Rutherford, M.J., Valavanis, K.P., 2013. A survey of unmanned aerial vehicles (UAVs) for traffic monitoring. Proceedings of the 2013 International Conference of Unmanned Aircraft System (ICUAS), Atlanta, GA, USA, 2831 May 2013, IEEE: Atlanta, GA, USA, 2013, 221-234.

Lo Brutto, M., Garraffa, A., Meli, P., 2014. UAV platforms for cultural heritage survey: First results. ISPRS Ann. Photogramm. Remote Sens. Spat. Inf. Sci., II-5, 227-234. doi.org/10.5194/isprsannals-II-5-227-2014, 2014.

Ludwig, N., 2017. Vapotranspiration in Biological System by Thermal Imaging. Application of infrared to biomedical sciences, Eddie YK Ng and M. Etehadtavakol editors, Springer, ISBN 978-981-10-3147-2, 417-428. doi.org/10.1007/978-98110-3147-2_23.

Ludwig, N., Cabrini, R., Faoro, F., Gargano, M., Gomarasca, S., Iriti, M., Picchi, V., Soave, V., 2009. Reduction of evaporative flux in bean leaves due to chitosan treatment assessed by infrared thermography. Infrared Physics \& technology, 53, 6570. doi.org/10.1016/j.infrared.2009.08.008.

Lundén, B., 1985. Aerial Thermography: A remote sensing technique applied to detection of buried archaeological remains at a site in Delecarlia, Sweden. Geografiska Annaler. Series A, Physical Geography, 67(1/2), 161-166.

Martínez-Lüscher, J., Kizildeniz, T., Vu`ceti'c, V., Dai, Z., Luedeling, E., van Leeuwen, C., Gomès, E., Pascual, I., Irigoyen, J.J., Morales, F., et al., 2016. Sensitivity of Grapevine Phenology to Water Availability, Temperature and $\mathrm{CO}_{2}$ Concentration. Front. Environ. Sci., 4 doi.org/10.3389/fenvs.2016.00048.

Masiero, A., Chiabrando, F., Lingua, A. M., Marino, B. G., Fissore, F., Guarnieri, A., and Vettore, A., 2019. 3D modeling of Girifalco fortress. Int. Arch. Photogramm. Remote Sens. Spatial Inf. Sci., XLII-2/W9, 473-478, doi.org/10.5194/isprsarchives-XLII-2-W9-473-2019.

Matese, A., Toscano, P., Di Gennaro, S., Genesio, L., Vaccari, F., Primicerio, J., Belli, C., Zaldei, A., Bianconi, R., Gioli, B., 2015. Intercomparison of UAV, Aircraft and Satellite Remote Sensing Platforms for Precision Viticulture. Remote Sens., 7, 2971-2990. doi.org/10.3390/rs70302971.

Milazzo, M., Ludwig, N., Villani, S., Soave, C., Cicardi, C., 1994. Applicability of IR thermography to measurement of leaf transpiration. Atti della fondazione Giorgio Ronchi "Advanced Infrared Technology and Applications" n.1, 1994, 171-180.

Mouget, A., Lucet, G., 2014. Photogrammetric archaeological survey with $U A V$, Proceeding of ISPRS Annals of the Photogrammetry, Remote Sensing and Spatial Information Sciences, Volume I-5, 23-25 June 2014 Riva del Garda, Italy, 2014, 251-258. doi.org/10.5194/isprsannals-II-5-251-2014

Nebiker, S., Lack, N., 2016. Multispectral and thermal sensors on UAVs, GIM International, UAS special, 14-17.

Rinaudo, F., Chiabrando, F., Lingua, A., Spanò, A., 2012. Archaeological site monitoring: UAV photogrammetry can be an answer. ISPRS Int. Arch. Photogramm. Remote Sens. Spat. Inf. Sci., XXXIX-B5, 583-588. doi.org/10.5194/isprsarchivesXXXIX-B5-583-2012.

Singh, V., Misra, A.K., 2017. Detection of plant leaf diseases using image segmentation and soft computing techniques. Information Processing in Agriculture, 4 (1), 41-49. doi.org/10.1016/j.inpa.2016.10.005.

Socci, P., Errico, A., Castelli, G., Penna, D., Preti, F., 2019. Terracing: From Agriculture to Multiple Ecosystem Services. In Oxford Research Encyclopedia on Agriculture; in press.

Svensgaard, J., Roitsch, T., Christensen, S., 2014. Development of a Mobile Multispectral Imaging Platform for Precise Field Phenotyping. Agronomy, 4, 322-336. doi.org/10.3390/agronomy4030322

Tucci, G., Parisi, E.I., Castelli, G., Errico, A., Corongiu, M., Sona, G., Viviani, E., Bresci, E., Preti, F., 2019. Multi-Sensor UAV Application for Thermal Analysis on a Dry-Stone Terraced Vineyard in Rural Tuscany Landscape. ISPRS Int. J. Geo-Inf., 8 (87), 1-21. doi.org/10.3390/ijgi8020087.

Turner, D., Lucieer, A., Watson, C., 2011. Development of an Unmanned Aerial Vehicle (UAV) for hyper resolution vineyard mapping based on visible, multispectral, and thermal imagery. Proceedings of $34^{\text {th }}$ International Symposium on Remote Sensing of Environment, 2011.

Wei, W., Chen, D., Wang, L., Daryanto, S., Chen, L., Yu, Y., Lu, Y., Sun, G., Feng, T., 2016. Global synthesis of the classifications, distributions, benefits and issues of terracing. $\begin{array}{lll}\text { Earth-Sci. Rev., 338-403. } & \text {. }\end{array}$ doi.org/10.1016/j.earscirev.2016.06.010.

Yazici, K., Kalayci Onaç, A., Gulgun Aslan, B., 2018. The importance of UAV (Drone) Usage According to Landscape Architecture, Proceedings book of the International Maemara Science and social Sciences Congress, 23-25 November 2018, Kocaeli, Turkey, 1428-1438.

Zarco-Tejada, P.J., Camino, C., Beck, P.S.A., Calderon, R., Hornero, A., Hernandez-Clemente, R., Kattenborn, T., MontesBorrego, M., Susca, L., Morelli, M., Gonzalez-Dugo, V., North, P.R.J., Landa, B.B., Boscia, D., Saponari, M., Navas-Cortes, J.A., 2018. Previsual symptomps of Xylella fastidiosa infection revealed in spectral plant-trait alterations. Nat Plants, 4(7), 432439. doi.org/10.1038/s41477-018-0189-7.

Zefri, Y., Elkettani, A., Sebari, I., and Ait Lamallam, S., 2018. Thermal Infrared and Visual Inspection of photovoltaic Installations by UAV Photogrammetry-Application Case: Morocco. Drones, 2, 41. doi.org/10.3390/drones2040041. 